\title{
OPEN Rapid and accurate electrochemical sensor for food allergen detection in complex foods
}

\author{
Madanodaya Sundhoro, Srikanth R. Agnihotra, Nazir D. Khan, Abigail Barnes, \\ Joseph BelBruno \& Lukasz Mendecki ${ }^{凶}$
}

Food allergies are estimated to affect about $2-5 \%$ of adults and $6-8 \%$ of children, globally. Currently, the most effective strategy for food allergy management is stringent avoidance of the offending allergen. Unlike other major food allergens, soy is uniquely challenging to avoid due to its prevalence and insidiousness in a wide variety of foods, such as infant formulas. Recently, we demonstrated a simple, accurate, and consumer-friendly sensor using molecularly imprinted polymers (MIPs) for rapid detection of soy allergenic tracers in complex food matrices at clinically relevant levels. In this work, we build on these findings by subjecting MIP-based soy allergen sensors to test trials in 42 different food products, representing over 300 ingredients. Foods were selected based on their compositional complexity to capture a wide range of preparatory methods and processing conditions. In each case, the Allergy Amulet correctly reported on the presence or absence of soy allergen tracer in investigated samples and were subjected to immunoassay confirmatory analysis. The outcome of this research will help resolve persistent difficulties with commercial technologies in detecting allergenic tracers with minimal cross-interference in foods, and will give those with soy allergies the ability to easily, rapidly, and accurately identify and avoid foods with soy allergens.

Soybean is one of the most common sources of dietary protein due to its reported health benefits, functional properties, and high nutritional value ${ }^{1,2}$. Soy is typically introduced into the diet early in life, often in the form of infant formula, as a substitute to human or cow milk for lactose intolerant infants ${ }^{3,4}$. Despite its reported nutritional benefits, soy is also an important source of food allergens. Soy allergy is among the eight most common forms of food allergy, and in severe cases it can trigger life-threatening anaphylaxis ${ }^{5}$. The estimated prevalence of soy allergy ranges from 0.8 to $1.2 \%$ in children and from 0.3 to $0.4 \%$ in adults, currently affecting approximately 1.9 million Americans, including 0.4 million children ${ }^{6,7}$. Since soy is nearly omnipresent in processed foods today, consuming soy-based products is essentially unavoidable unless one makes a concerted effort to read labels carefully, and effectively communicates the allergy to those preparing one's food-even then, the risk of inadvertent ingestion remains.

Currently, no preventative solutions are available for soy allergy sufferers other than strict avoidance. In response, countries have developed legislations and allergen management strategies, requiring manufacturers to identify allergen ingredients on labels to alert consumers on the presence or absence of allergen. In the US, the Food Allergen Labeling and Consumer Protection Act (FALCPA) identifies eight food allergens, including soy, milk, egg, peanut, shellfish, fish, wheat, and tree nuts, that must be identified on the food label ${ }^{8}$. More recently, sesame was added to this list ${ }^{9}$. Even when assuming strict precautionary measures, consumers face a high risk of accidental allergen exposure from adulterated products, undeclared substances, and cross-contamination. A low-cost, accurate, rapid, and consumer-friendly solution for detecting allergens in foods would help account for these risks through greater food transparency and would provide consumers with greater assurances that their foods are safe.

To date, the most widely employed methods for food allergen detection include enzyme-linked immunosorbent assays (ELISA), lateral flow devices (LFDs), and polymerase chain reaction (PCR). ELISA and LFDs both use monoclonal or polyclonal antibodies to recognize and capture targeted allergens, while PCR relies on detecting DNA fragments of the allergenic species ${ }^{10-12}$. Although many detection kits based on the ELISA, PCR, and LFDs technologies have been successfully commercialized ${ }^{13}$, these methods present several practical limitations undermining the credibility of test results. Among them is the denaturation and/or degradation of proteins and DNA fragments during food processing, which can yield false negative responses ${ }^{11,14,15}$. In addition, antibodies used in the production of immunological bioassays often demonstrate limited thermal stability ${ }^{16}$, are expensive 
to manufacture, and can cross-react ${ }^{17}$ with other matrix components, which may produce false positive or false negative responses ${ }^{11}$. While LFD strips are arguably the closest assay to a consumer device in terms of simplicity and ease of use, these tests often demonstrate low detection accuracy ${ }^{18}$, requiring multiple samples to verify accuracy. Additionally, changes in food viscosity and texture are known to strongly influence the accuracy of LFD strips in food allergen analysis ${ }^{19}$. Existing commercial detection systems are accordingly ill-equipped for consumer use, and underscore the need for a consumer device capable of rapidly and accurately detecting common allergenic ingredients on-site in food samples.

Recently, we demonstrated the first application of molecularly imprinted polymers (MIPs) to achieve electrochemical detection of soy in complex foods, through detecting a soy allergen marker: genistein ${ }^{20}$. These sensors correctly reported on the presence of soy in food samples subjected to both MIP and LFD measurements. Herein, we carried out the first demonstration of imprinted polymer technology detecting allergens in a large number of foods with varying levels of complexity and homogeneity (e.g., meats, sauces, confectionary, grains, curries, liquids, etc.) prepared under a variety of processing conditions including heat, fermentation, and acidity. For this purpose, we selected 42 food products representing store purchased foods and restaurant products. Together, these foods consist of over 300 ingredients (Supplementary Table S1). In each case, our technology correctly reported on the presence or absence of soy in food samples subjected to the standard LFD allergen detection measurements, demonstrating the effectiveness of our sensors in a diverse range of chemical environments, and the potential of MIP-based technology as a new benchmark for rapid and accurate allergen detection applications.

\section{Materials and Methods}

Genistein was purchased from BOC Sciences (Shirley, NY). Ortho-phenylenediamine (o-PD), catechin hydrate, chrysin, acetic acid, and sodium acetate were purchased from Sigma-Aldrich (Milwaukee, WI). Amygdalin and juglone (5-hydroxy-1,4-napthquinone) were purchased from Alfa Aesar (Tewksbury, MA). Denatured ethanol (5\% IPA, 5\% n-propylacetate) was purchased from Oakwood Chemicals (Estill, SC). PBS 10X (pH=7.4) was sourced from Boston Bioproducts (Boston, MA). All reagents were of analytical grade and were used without

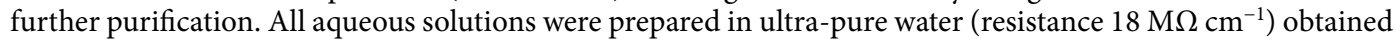
from Satorius arium mini plus Ultrapure Water System (Germany). $1 \times$ PBS solutions were prepared by performing a 1:10 dilution of $10 \times$ PBS in ultrapure water.

Electrochemical experiments were conducted with a PalmSens4 potentiostat (Palm Instruments BV, Netherlands). Carbon ItalSens IS-C Screen Printed Electrodes (SPE) were purchased from PalmSens (Houten, Netherlands) and were used during all electrochemical measurements. Our allergen sensors, which are part of the Allergy Amulet platform detection system, were prepared according to the method previously developed in our laboratory (Supplementary Experimental S1) ${ }^{20}$.

Food samples. Store purchased goods included soy curls (Butler), soybeans (Soymerica), tofu (Housefoods), soy sauce (Kim Ve Wong), vegetable oil (Hannaford), Roasted Garlic Parmesan Sauce (Ragu), Captain's Wafers Cream Cheese and Chives (Lance), Thousand Island dressing (Ken's Steak House), soy protein isolate (Now), granola protein (Nature Valley), soy lecithin (Modernist Pantry), Ritz Crackers with Cheese (Nabisco), Lemon Flavor Crème Oreo (Nabisco), Toast Chee Peanut Butter Crackers (Lance), veggie burger (Morning Star Farms), soy flour (Bob's Red Mill), defatted soy flour (Scratch), Chicken (Not!) (Dixie Diner's Club), Zante currant raisins (Sunmaid), tikka masala (Patak's), sesame seeds (McCormick), rice milk (Rice Dream), red wine vinegar (Market Basket), raisins (Sunmaid), Pure butter shortbread (Walkers), peanut oil (Hain), Moroccan tomato sauce (Mina), mayonnaise (Hellman's), Major Grey chutney (Patak's), Original macadamia milk (Milkadamia), Growing Years whole milk (Horizon Organic), green salsa (Mrs. Renfro's), flax milk (Good Karma), fish sauce (Thai Kitchen), Country French with Orange Blossom Honey dressing (Ken's Steak House), Coffee Mate creamer (Nestle), cashew milk (So Delicious), Breakfast Blend light roast coffee (Green Mountain), and almond milk (Nature's Promise) were sourced from local supermarkets. Restaurant dishes, including Ming's Bings Veggie-Filled Bing patty, duck fried rice and garlic ginger bok choy were sourced from Blue Dragon restaurant (Boston, MA). Confirmatory LFDs measurements were performed using a Soy Rapid Kit L25SOY LFD kit purchased from $3 \mathrm{M}$.

Food testing method. For each solid food tested, $1 \mathrm{~g}$ of food was homogenized using a mortar and pestle ( $5 \mathrm{~min}$ ) until a fine powder was obtained. The resulting powder was then mixed with $10 \mathrm{~mL}$ of buffer solution and stirred for $15 \mathrm{~min}$. Liquid food samples were prepared by mixing $1 \mathrm{~g}$ of food directly with $10 \mathrm{~mL}$ of the buffer solution. For both solid and liquid food tests, template-extracted MIP electrodes were inserted into a $10 \mathrm{~mL}$ of the buffer solution and equilibrated for $5 \mathrm{~min}$ prior to the electrochemical measurements. The electrode was then taken out of the solution and the liquid was removed from the surface. After 1 min incubation with $100 \mu \mathrm{L}$ of sample solution, the electrodes were subjected to differential pulse voltammetry (DPV) measurements. DPV experimental parameters: scan rate: $50 \mathrm{mV} / \mathrm{s}$; pulse width: $50 \mathrm{~ms}$; and amplitude: $50 \mathrm{mV}$. All food measurements were run at least in triplicate. Imprinting factor was calculated by dividing signal intensity of MIP with a nonimprinted polymer (NIP) at their peak current maxima (peak position: $0.6 \mathrm{~V}$ vs Ag/AgCl reference electrode). A positive response was noted when the sensor reported on the presence of an oxidation peak at approximately $0.60 \mathrm{~V}$ vs Ag/AgCl and an imprinting factor above 1.3, which corresponds to oxidative redox transformations of genistein (Fig. 1A) ${ }^{20}$. This electrochemical behavior is consistent with the studies of Popa and Diculescu ${ }^{21}$ and our earlier work ${ }^{20}$.

LFD testing method. LFDs measurements were carried out according to the $3 \mathrm{M}$ protocol (Fig. 1B) $)^{22}$. Briefly, $100 \mu \mathrm{L}$ of liquid food samples were mixed with $900 \mu \mathrm{L}$ of $3 \mathrm{M}$ extraction buffer and vortexed for $15 \mathrm{~s}$ to 
$\mathbf{A}$ Allergy Amulet

$(+)$

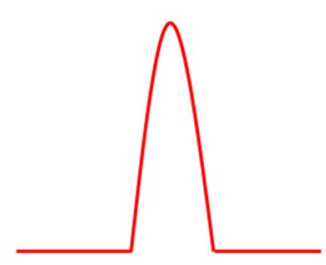

$(-)$
B

$(+)$

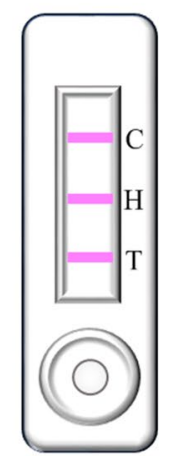

3M Soy Protein Rapid Kit

$(-) \quad$ Concentrated
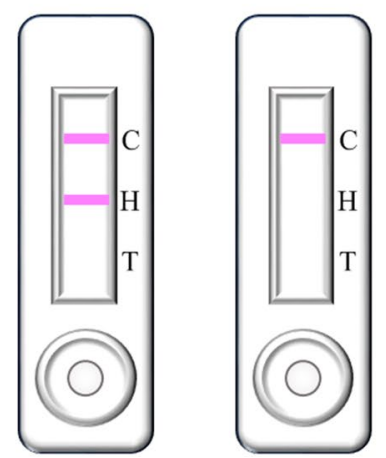

Invalid

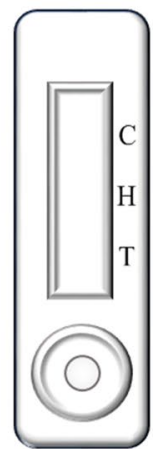

Figure 1. Illustrative responses from: Allergy Amulet kit (A) and 3 M Soy Protein Rapid kit (B). The Allergy Amulet sensor records a positive reading when a distinct oxidation peak for soy allergen tracer is present at approximately $0.60 \mathrm{~V}$ vs Ag/AgCl reference electrode. For the LFD test kits a positive result is visualized by the presence of three lines: a control line $(\mathrm{C})$, a hook line $(\mathrm{H})$ and a test line $(\mathrm{T})$. Negative LFDs results were indicated by the presence of a control and a hook line only. Concentrated LFDs results were indicated by the presence of control line while the invalid results were indicated by the absences of all of three lines.

aid extraction. $100 \mu \mathrm{L}$ of the resulting food mixture was then introduced to the $3 \mathrm{M}$ Soy Protein LFD sample well and left to incubate for $11 \mathrm{~min}$. Solid food samples were prepared by homogenizing $1 \mathrm{~g}$ of food, using a mortar and pestle, for $5 \mathrm{~min} .1 .8 \mathrm{~mL}$ of the $3 \mathrm{M}$ extraction buffer was then added into a microcentrifuge tube containing $0.2 \mathrm{~g}$ of the homogenized samples. The resulting mixture was vortexed for $15 \mathrm{~s}$ until the sample was well dispersed prior to $30 \mathrm{~s}$ centrifugation at 10,000 rpm using Bio Lion XC-10K. A suspension sample of $100 \mu \mathrm{L}$ was then introduced into the well of the $3 \mathrm{M}$ Soy Protein LFD and left to incubate for $11 \mathrm{~min}$.

Cross-reactivity studies. For cross-reactivity measurements, a stock solution with concentration of $1 \mathrm{mg} /$ $\mathrm{mL}$ was prepared by dissolving $5 \mathrm{mg}$ of the interferent molecule (amygdalin, juglone, chrysin, or catechin) in $5 \mathrm{~mL}$ of ethanol for $15 \mathrm{~min}$. A $10 \mathrm{ppm}$ solution of each interferent was prepared by adding $100 \mu \mathrm{L}$ of stock solution $(1 \mathrm{mg} / \mathrm{mL})$ into a solution containing $900 \mu \mathrm{L}$ of ethanol and $9 \mathrm{~mL}$ of PBS $1 \times .10 \mathrm{ppm}$ solutions of both the soy allergen tracer and the analogous molecule were formed by adding $100 \mu \mathrm{L}$ of soy allergen tracer stock solution and $100 \mu \mathrm{L}$ of interference stock solution followed by adding $800 \mu \mathrm{L}$ of ethanol and $9 \mathrm{~mL}$ of PBS $1 \times$ with $15 \mathrm{~min}$ of stirring. DPV measurements were conducted using the same parameters as those used for food testing.

\section{Results and discussion}

Processing and cooking can subject an allergen to denaturation and other conformational changes, which can reduce - but will not necessarily remove completely_its potential to trigger an allergic response. Additionally, allergens may be entrapped or physically constrained to their environment, inhibiting dissolution and/or binding to the selective cavities of the polymer. For the sensor to be effective, it must detect the presence of the allergen regardless of its chemical environment. In this study, we validated the effectiveness of the Allergy Amulet by testing the sensor against 20 different foods known to contain soy and 22 different foods not containing soy. For store-purchased products and restaurant dishes, information on the presence or absence of soy allergen was collected directly from food ingredients used and allergen labels. The integrity of the results requires confirmation of the presence of the allergen in the food by extant allergen detection technology. This was performed using commercially available immunoassay methods (LFDs).

The detection of allergens in food products strongly depends on efficient extraction of soy allergen tracer from complex food matrices. Food processing is known to cause allergen denaturation, conformational changes, aggregation, or chemical modifications ${ }^{15}$. These changes have been reported to strongly influence allergen extractability and antibody recognition of allergenic proteins or DNA fragments in immunoassay or PCR analysis. Conversely, genistein (soy allergen tracer) has been shown to retain its structural stability after being subjected to extensive food processing treatments, including heating and fermentation ${ }^{23,24}$. This approach enables detection of soy in foods even when the DNA and/or the allergenic protein was altered or degraded after food processing. This property is important since it has been reported that soybean can retain its allergenicity even after food processing 25 .

To better understand the impact of food texture and composition on the extractability of soy allergen tracer from foods, we have created a four-point rating scale for grouping different foods by their textural characteristics including crispiness, tenderness, smoothness, toughness, chewiness, creaminess (Table 1). The following ratings were assigned for all tested foods: (1) liquids (soy sauce, vegetable oil, rice milk, red wine vinegar, peanut oil, Original macadamia milk, growing years whole milk, flax milk, fish sauce, Coffee Mate creamer, cashew milk, Breakfast Blend light roast coffee, and almond milk); (2) viscous liquids and emulsions (Roasted Garlic Parmesan Sauce, Thousand Island dressing, tikka masala, Moroccan tomato sauce, mayonnaise, Major Grey chutney, green salsa, Country French with Orange Blossom and Honey dressing); (3) gelatinous substances 


\begin{tabular}{|c|c|c|c|c|c|c|c|c|}
\hline Entry & Food & Brand & Number of ingredients $\mathrm{s}^{\mathrm{a}}$ & Presence of soy ${ }^{a}$ & Source of soy ${ }^{a}$ & Texture $^{\mathrm{b}}$ & MIP results ${ }^{c}$ & LFD results \\
\hline 1 & $\begin{array}{l}\text { Thousand island } \\
\text { dressing }\end{array}$ & Ken’s Steak House & 36 & Yes & Soybean oil & 2 & Negative & Negative \\
\hline 2 & Almond milk & Nature's Promise & 10 & No & - & 1 & Negative & Negative \\
\hline 3 & $\begin{array}{l}\text { Breakfast blend light } \\
\text { roast coffee }\end{array}$ & Green Mountain & 1 & No & - & 1 & Negative & Negative \\
\hline 4 & $\begin{array}{l}\text { Captain's wafers cream } \\
\text { cheese and chives }\end{array}$ & Lance & 30 & Yes & Soybean oil & 4 & Negative & Negative \\
\hline 5 & Cashew milk & So Delicious & 14 & No & - & 1 & Negative & Negative \\
\hline 6 & Chicken (Not!) & Dixie Diner's Club & 1 & Yes & Soy flour & 4 & Positive & Concentrated \\
\hline 7 & Coffee mate creamer & Nestle & 8 & No & - & 1 & Negative & Negative \\
\hline 8 & $\begin{array}{l}\text { Country French with } \\
\text { orange blossom honey } \\
\text { dressing }\end{array}$ & Ken' Steak House & 16 & No & - & 2 & Negative & Negative \\
\hline 9 & Defatted soy flour & Scratch & 1 & Yes & Soy flour & 3 & Positive & Concentrated \\
\hline 10 & Duck fried rice & Blue Dragon Restaurant & 15 & Yes & Soy sauce & 3 & Negative & Negative \\
\hline 11 & Fish sauce & Thai Kitchen & 3 & No & - & 1 & Negative & Negative \\
\hline 12 & Flax milk & Good Karma & 12 & No & - & 1 & Negative & Negative \\
\hline 13 & Garlic ginger bok choy & Blue Dragon Restaurant & 6 & No & - & 3 & Negative & \begin{tabular}{|l} 
Negative \\
\end{tabular} \\
\hline 14 & Granola protein & Nature Valley & 11 & Yes & Soy protein isolate & 4 & Positive & Concentrated \\
\hline 15 & Green salsa & Mrs. Renfro's & 7 & No & - & 2 & Negative & Negative \\
\hline 16 & $\begin{array}{l}\text { Growing years whole } \\
\text { milk }\end{array}$ & Horizon Organic & 7 & No & - & 1 & Negative & Negative \\
\hline 17 & $\begin{array}{l}\text { Lemon flavor crème } \\
\text { oreo }\end{array}$ & Nabisco & 15 & Yes & Soy lecithin & 4 & Negative & Negative \\
\hline 18 & $\begin{array}{l}\text { Original macadamia } \\
\text { milk }\end{array}$ & Milkadamia & 11 & No & - & 1 & Negative & Negative \\
\hline 19 & Major grey chutney & Patak's & 13 & No & - & 2 & Negative & Negative \\
\hline 20 & Mayonnaise & Hellmann's & 8 & No & - & 2 & Negative & Negative \\
\hline 21 & Veggie filled Ming's Bing & Blue Dragon Restaurant & 22 & Yes & Soy sauce & 22 & Positive & Positive \\
\hline 22 & Moroccan tomato sauce & Mina & 8 & No & - & 2 & Negative & Negative \\
\hline 23 & Peanut oil & Hain & 2 & No & - & 1 & Negative & Negative \\
\hline 24 & Pure butter shortbread & Walkers & 8 & No & - & 4 & Negative & Negative \\
\hline 25 & Raisin & Sunmaid & 1 & No & - & 3 & Negative & Negative \\
\hline 26 & Red wine vinegar & Market Basket & 1 & No & - & 1 & Negative & Negative \\
\hline 27 & Rice milk & Rice Dream & 8 & No & - & 1 & Negative & Negative \\
\hline 28 & $\begin{array}{l}\text { Roasted garlic parmesan } \\
\text { sauce }\end{array}$ & Ragu & 25 & Yes & Soybean oil & 2 & Negative & Negative \\
\hline 29 & Ritz crackers with cheese & Nabisco & 25 & Yes & Soy lecithin & 4 & Negative & Negative \\
\hline 30 & Sesame seeds & McCormick & 1 & No & - & 4 & Negative & Negative \\
\hline 31 & Soy curls & Butler & 1 & Yes & Soybeans & 4 & Positive & Concentrated \\
\hline 32 & Soy flour & Bob’s Red Mill & 1 & Yes & Soy flour & 3 & Positive & Concentrated \\
\hline 33 & Soy lecithin & Modernist Pantry & 1 & Yes & Soy lecithin & 3 & Negative & Concentrated \\
\hline 34 & Soy protein isolate & Now & 1 & Yes & Soy protein isolate & 3 & Positive & Concentrated \\
\hline 35 & Soy sauce & Kim Ve Wong & 5 & Yes & Soybeans & 1 & Positive & Negative \\
\hline 36 & Soybeans & Soymerica & 1 & Yes & Soybeans & 4 & Positive & Positive \\
\hline 37 & Tikka masala & Patak's & 20 & No & - & 2 & Negative & Negative \\
\hline 38 & $\begin{array}{l}\text { Toast chee peanut butter } \\
\text { crackers }\end{array}$ & Lance & 25 & Yes & Soy lecithin, soybean oil & 4 & Negative & Weak Positive \\
\hline 39 & Tofu & Housefoods & 4 & Yes & Soybeans & 3 & Positive & Positive \\
\hline 40 & Vegetable oil & Hannaford & 1 & Yes & Soybean oil & 1 & Negative & Negative \\
\hline 41 & Veggie burger & Morning star farms & 27 & Yes & $\begin{array}{l}\text { Soy flour, soy sauce } \\
\text { powder }\end{array}$ & 3 & Positive & Positive \\
\hline 42 & Zante currant raisin & Sunmaid & 1 & No & - & 3 & Negative & Negative \\
\hline
\end{tabular}

Table 1. Detection responses recorded for MIP-coated electrodes and LFDs during food product measurements. A positive test result for both MIP and LFD kit detection confirms that soy allergen is present within a tested sample. ${ }^{a}$ As reported in ingredients lists. ${ }^{b}$ Based on scale 1-4 with 1 liquid, 2 viscous liquid and emulsions, 3 gelatinous and soft solid, 4 hard solid. ${ }^{c}$ Based on triplicated electrochemical readings. 
and soft-solids (tofu, duck fried rice, soy protein isolate, soy lecithin, veggie burger, soy flour, defatted soy flour, Zante currant raisin, raisin, and garlic ginger bok choy); and (4) hard solids (soy curls, soybeans, Captain's Wafers Cream Cheese and Chives, granola protein, Ritz Cracker with Cheese, Lemon Flavor Crème Oreo, Toast Chee peanut butter crackers, Chicken (Not!), sesame seeds, and Pure butter shortbread) (Table 1). For soy containing foods, we further subcategorized these products based on the origin and source of the soy protein used for their preparation, including soybeans, soy flour, soy protein isolate, soy sauce, tofu, soy lecithin, and soybean oil. We then tested the electrochemical response of MIP-coated electrodes in $10 \%$ ethanol, $90 \% 1 \times \mathrm{PBS}(\mathrm{v} / \mathrm{v}, \mathrm{pH} 7.4)$ solutions containing $10 \%$ by weight of each of the food product representing different textures and soy origins. DPV measurements recorded for soy protein isolate, soy flour, defatted soy flour, tofu, and soybeans showed distinct oxidation peak for soy allergen tracer at approximately $0.6 \mathrm{~V}$ (Supplementary Figs. S1-S4) which is consistent with the analyte-centered redox activity of genistein ${ }^{20,21}$. Similarly, positive detection was recorded for soy curls and Chicken (Not!) chunks (Table 1), which contain mainly soybeans or soy flour, respectively. While LFD measurements also reported a positive response for the soybeans, the 3 M LFD test kit failed to inform on the presence of soy allergens in soy protein isolate, soy curls, Chicken (Not!), and tofu (Supplementary Fig. S5A-D), giving rise to a concentrated readout (invalid). The lack of response for LFDs could be caused by protein oversaturation at the detection site, the area at which the biological recognition elements (antibodies, proteins, enzymes, etc.) are immobilized. To overcome this problem, the sample solution-prepared according to the manufacturer's specifications-had to be repeatedly diluted to achieve the right concentration and enable detection of a soy allergen using LFD. The differences in response characteristics of LFD strips between the soy protein isolate, soy curls, Chicken (Not!) chunks, and the soybeans may be partially attributed to their textural variability. When matured, soybeans can be characterized as a dry and hard solid, which can limit its grinding efficiency using mortar and pestle. Indeed, the other soy-containing hard foods are easier to process using mortar and pestle. As a result, manual processing of soybeans did not yield a well homogenized and homogenous powder, contributing to inefficient extraction of allergenic proteins from soybean particles.

Further, LFD measurements did not register a positive response for soy flour samples (Supplementary Fig. $\mathrm{S} 5 \mathrm{~F}$ ). This inconclusive result may be attributed to the increased viscosity of the tested solution, inhibiting the fluid flow across the LFD substrate even after hours of incubation. While diluting the soy flour solution four times enabled the movement of the liquid to the detection area, the device still reported a concentrated result (Supplementary Fig. S5G). The susceptibility of tested LFDs to produce positive responses in soy-rich foods poses practical limitations if such products were to be used in consumer allergen testing applications, as the user would in theory be required to undertake extensive sample processing steps, and run multiple measurements to realize accurate detection.

We then tested the electrochemical response of MIP-coated electrodes for two soy-labelled liquid products: soy sauce and soybean oil. The DPV measurements of soy sauce and soybean oil did not reveal a characteristic response for soy tracer at $0.60 \mathrm{~V}$, but instead generated a smaller signal at approximately $0.80 \mathrm{~V}$ for soy sauce containing samples. The observed peak current at higher anodic potentials may be due to the presence of polyphenols in soy sauce ${ }^{26}$. Confirmatory LFDs tests also reported a negative responses for soy sauce (Supplementary Fig. S5H) and soybean oil samples (Supplementary Fig. S5I). These experimental observations can most likely be explained by very low content of allergenic soy protein, resulting from the industrial fermentation processes (e.g., microbial proteolytic enzymes) used for the manufacturing of many soy sauces. Indeed, food processing is known to reduce the allergenicity of soy and wheat proteins in processed foods ${ }^{27}$. Similarly, the industrial processes of refining soybean oil typically involve multiple extraction steps using hot solvents, bleaching, and deodorization, which serve to effectively eliminate the allergenic soy protein from the soybean oil-based products. Additionally, it has been showed that soybean oil is generally safe to consume for soy allergenic individuals ${ }^{28}$. Unlike the positive results, obtaining negative results is quite straightforward in LFDs. In most cases, clear hook and control lines are easily observable. In most foods containing soy allergen, LFD results tend to give concentrated or faint signals on both the hook line and the test line. A positive or invalid result in these cases would be subject to the perception of the interpreter.

Lastly, we studied the response of our sensors when testing soy lecithin. Soy lecithin is a common soy-based additive used in the food industry as an emulsifier, lubricant, antioxidant, and flavor protector. Because soy lecithin is produced from highly refined soy oils, it typically contains insufficient amounts of allergenic soy protein to provoke allergic reactions in most soy-allergic individuals. For example, the Food \& Drug Administration (FDA) has granted exemptions regarding the labelling of soy lecithin as an allergen on food products. These exemptions apply when soy lecithin is used directly as a release agent or a component of a release agent applied to food contact surfaces ${ }^{29}$. DPV measurements with MIP-coated electrodes on soy lecithin reported a negative response as evidenced by the lack of an anodic peak at $0.6 \mathrm{~V}$ vs Ag/AgCl reference electrode. Like soy flour, LFD tests produced an inconclusive readout - the liquid could not readily travel from the loading well to the detection site (Supplementary Fig. S5J). Although, LFDs have been widely regarded as rapid and portable food tests, these are highly susceptible to the presence of matrix components and overall sample consistency which together can cause pore obstruction, and thus limit the liquid flow. After carrying out additional sample dilutions (tenfold), the resulting "slurry" was of the right consistency to produce a visible readout using immunoassay analysis. The confirmatory LFD strips also reported a negative response, indicating the absence of soy allergenic protein at clinically relevant levels in tested soy lecithin samples (Supplementary Fig. S5K).

Grocery store foods. After studying the influence of food texture and composition on detection performance of the Allergy Amulet sensor, we focused our attention on expanding the range and number of use cases in food allergen analysis applications. We accordingly selected 21 soy-free and 18 soy-containing store-bought products, each prepared using a different manufacturing process and having a unique composition (Supplemen- 


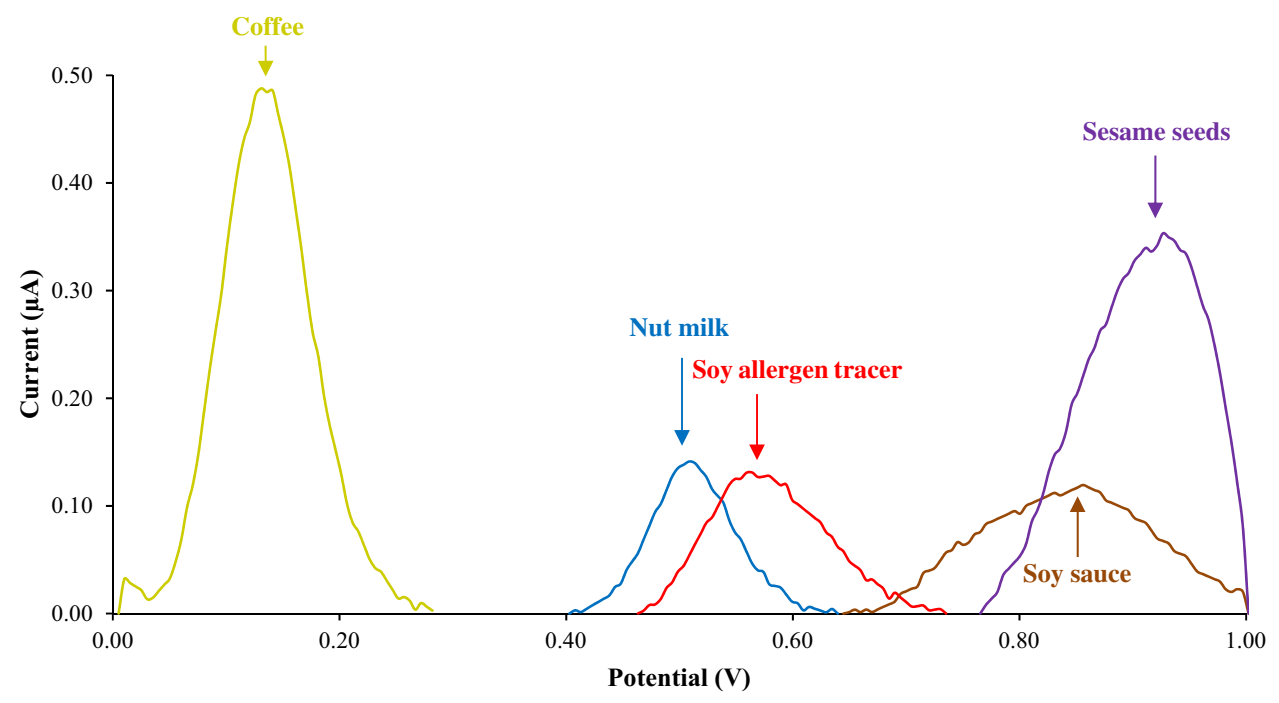

Figure 2. DPV responses for soy allergen tracer (red line), soy sauce (brown line), sesame seeds (purple line), coffee (gold line), nut milk (blue line) $10 \%$ by weight in buffer solution containing $10 \%$ ethanol in $90 \%$ PBS $1 \times$.

tary Table S1). Electrochemical measurements of Captain's Wafers Cream Cheese \& Chives sandwich crackers, Toast Chee Peanut Butter Crackers, and Ritz Crackers with Cheese reported a negative response as evidenced by the lack of a characteristic signal for soy allergen tracer at $0.6 \mathrm{~V}$ vs Ag/AgCl. As the primary source of soy in these foods is soy lecithin, these results were consistent with our earlier data obtained from soy lecithin measurements. While the LFD tests on the Captain's Wafers Cream Cheese \& Chives and Ritz Crackers with Cheese confirmed the absence of soy allergen in each food, the immunoassay reported a slightly positive readout for Toast Chee Peanut Butter Crackers samples (Supplementary Fig. S1L). This result was unexpected, as the only soy-based ingredient in Toast Chee Peanut Butter Crackers identified by the manufacturer and listed on a food label was soy lecithin. The faint positive signal recorded in LFD analysis of Toast Chee Peanut Butter Crackers may be due to the "fatty or smeary" nature and texture of the food. These compositional and textural characteristics have been already reported to influence the accuracy of LFDs in detecting allergens, giving rise to false positive readouts ${ }^{30}$.

Lemon Flavor Crème Oreo is another food containing soy lecithin as its soy source. DPV measurements of Lemon Flavor Crème Oreo sandwich cookies did not report on the presence of soy allergen tracer at $0.6 \mathrm{~V}$, but instead a weak anodic signal was observed at $0.5 \mathrm{~V}$ vs $\mathrm{Ag} / \mathrm{AgCl}$. The recorded electrochemical signal at a more cathodic potential may be due to the presence of annatto extract in tested cookies. Annatto is a common food dye known to contain redox-active polyphenols ${ }^{31}$. The LFD measurements also did not produce a positive response during testing of Lemon Flavor Crème Oreo sandwich cookies samples, indicating the high accuracy of our MIP-based sensors. Subsequently, we subjected MIP-coated electrodes to food measurements with two soy-containing solid food products: soy burger patties and granola protein bars. Soy flour and soy protein isolate were identified as the primary sources of soy in each respective formulation. Using Allergy Amulet and LFD immunoassays, we correctly identified the presence of soy in both tested samples. These findings were consistent with our earlier test results on soy flour and soy protein isolate. We then tested highly complex semi-liquid food samples (texture scale: 2) including Roasted Garlic Parmesan Sauce and Thousand Island dressing, consisting of 25 and 36 individual ingredients, respectively. The food labels indicated that both of these foods contained soy in the form of a soybean oil. Electrochemical and LFD measurements of these foods demonstrated a negative readout, matching those results obtained from earlier analysis on soybean oil samples.

Polyphenols, like genistein, are well-known antioxidant molecules found in several foods, herbs, and spices. These species are known to define some of the organoleptic characteristics of foods-e.g., color, flavor, and bitterness. The presence of phenolic moieties in polyphenols, being the main constituents of these compounds, confers their inherent redox activity and their antioxidant characteristics. As these molecules can demonstrate redox activity during electrochemical analysis, we investigated the detection capability of the MIP-based electrodes on molecules that are structurally similar to the soy allergen tracer that are present in significant quantities in foods (Supplementary Fig. S6). We then continued this investigation on a range of soy-free foods known to be rich in polyphenols, including coffee, nut milks (macadamia milk, flax milk and cashew milk), fish sauce, and sesame seeds ${ }^{26,32-39}$. Indeed, electrochemical measurements of these foods reported on the presence of anodic peaks at $0.1 \mathrm{~V}, 0.5 \mathrm{~V}, 0.8 \mathrm{~V}$ and $0.9 \mathrm{~V}$ vs $\mathrm{Ag} / \mathrm{AgCl}$ reference electrode, respectively (Fig. 2). No characteristic signal associated with the presence of soy allergen tracer $(0.6 \mathrm{~V})$ was detected during testing of soy-free foods with high polyphenol content. LFD analysis also reported on the negative response, indicating that such polyphenols had minimal interference on the accuracy of MIP-based sensors. These findings demonstrate that the differences in redox potentials of polyphenolic molecules make it possible to distinguish these analytes electrochemically from soy allergen tracer (Fig. 2). While other soy-free store purchased products including almond milk, rice 
milk, red wine vinegar, peanut oil, whole milk, Coffee Mate creamer, Pure butter short bread, raisins, and Zante currants may contain small levels of polyphenolic compounds, these foods did not produce any voltametric response in the investigated potential range $(0-1 \mathrm{~V})$. This effect might be caused by insufficient levels of these compounds to produce anodic signals in the extracted sample, as well as their redox processes taking place at more negative or positive potentials which fall outside the measurement range. These results demonstrate that our imprinted polymer-based sensors can successfully differentiate soy allergen tracer from other redox active species typically found in foods.

Restaurant dishes. Restaurant dishes are typically more complex than homemade foods or store-bought products in terms of their number of ingredients and textures. They are also an important category for validation due to the risk restaurant dining poses to allergy sufferers. Therefore, we selected one restaurant dish that was prepared without soy (garlic ginger bok choy) and two dishes prepared with soy (duck fried rice and veggie filled Ming's Bings Veggie-Filled Bing patty). Each dish was made up of at least seven individual ingredients and represented different cooking and processing methods (see Supplementary Table S1 for breakdown of ingredients). During garlic ginger bok choy measurements, the Allergy Amulet correctly reported on the absence of soy allergen tracer in tested foods subjected to immunoassay measurements (Table 1). Although, both duck fried rice and Ming's Bing patty have listed soy sauce as one of their ingredients, the Allergy Amulet and LFDs only reported a positive response for the Ming's Bing patty (Table 1). These results may be explained by the differences in the type $\mathrm{e}^{25}$ and amount of soy sauce used for preparing each individual dish.

After the original soy-free food samples were tested, they were "spiked" with a $10 \mathrm{ppm}$ solution of the allergenic tracer. The tests were then repeated to confirm the efficacy of the device in the food matrix now containing the allergen. In each case, our detection platform correctly identified the presence of soy allergen tracer in soy-spiked foods, showing minimal background interferences (data not shown).

\section{Conclusion}

In this work, we confirmed the feasibility of MIP-based sensors for soy allergen detection in complex foods. We selected food products that represented a wide range of sources (e.g., store-bought and restaurant dishes) and chose foods that ensured we could distinguish between those dishes containing soy and those that did not. For every food that was known to contain soy, Allergy Amulet correctly detected its presence at clinically relevant levels. To confirm that our sensor was performing at least as well as existing commercial allergen detectors, we then tested those same foods against a lateral flow device (LFD) — one of the key methods for testing allergenic ingredients in commerce. An exact binomial test was used to compare the binary accuracies of the MIP sensor and the LFD kit in detecting the presence of soy allergen, which confirmed the higher degree of accuracy of the MIP $(P=0.007)$. In particular, our sensors appeared to be superior in testing of highly concentrated soy-based products and foods with higher fat content. Therefore, we have determined that our MIP-based sensors are not only a suitable alternative to other analytical methods frequently used for food allergen testing, but also offers advantages in personal food allergen detection applications and food safety control that allow for detection in a broader range of conditions than were previously deemed possible.

Received: 13 June 2021; Accepted: 6 October 2021

Published online: 21 October 2021

\section{References}

1. Greiner, R. \& Konietzny, U. Presence of genetically modified maize and soy in food products sold commercially in Brazil from 2000 to 2005. Food Control 19, 499-505. https://doi.org/10.1016/j.foodcont.2007.05.016 (2008).

2. Rizzo, G. The antioxidant role of soy and soy foods in human health. Antioxidants 9, 635. https://doi.org/10.3390/antiox9070635 (2020).

3. Klemola, T. et al. Allergy to soy formula and to extensively hydrolyzed whey formula in infants with cow's milk allergy: A prospective, randomized study with a follow-up to the age of 2 years. J. Pediatr. 140, 219-224. https://doi.org/10.1067/mpd.2002.121935 (2002).

4. Zhang, T. et al. The development history and recent updates on soy protein-based meat alternatives. Trends Food Sci. Technol. 109, 702-710. https://doi.org/10.1016/j.tifs.2021.01.060 (2021).

5. Mills, E. N. C. \& Breiteneder, H. Food allergy and its relevance to industrial food proteins. Biotechnol. Adv. 23, 409-414. https:// doi.org/10.1016/j.biotechadv.2005.05.006 (2005).

6. Gupta, R. S. et al. The public health impact of parent-reported childhood food allergies in the United States. Pediatrics 142, e20181235. https://doi.org/10.1542/peds.2018-1235 (2018).

7. Gupta, R. S. et al. Prevalence and severity of food allergies among US adults. JAMA Netw. Open 2, e185630-e185630. https://doi. org/10.1001/jamanetworkopen.2018.5630\%JJAMANetworkOpen (2019).

8. Food Allergen Labeling and Consumer Protection Act (FALCPA) $\$ 108-282$ (2004). https://www.fda.gov/media/77570/downl oad. (Accessed 12 September 2021)

9. Food Allergy Safety, Treatment, Education and Research Act (FASTER Act) (2021). https://www.congress.gov/bill/117th-congr ess/senate-bill/578/all-info. (Accessed 12 September 2021)

10. Pedersen, M. H. et al. Soybean allergen detection methods-A comparison study. Mol. Nutr. Food Res. 52, 1486-1496. https://doi. org/10.1002/mnfr.200700394 (2008).

11. Scharf, A., Kasel, U., Wichmann, G. \& Besler, M. Performance of ELISA and PCR methods for the determination of allergens in food: An evaluation of six years of proficiency testing for soy (Glycine max L.) and wheat gluten (Triticum aestivum L.). J. Agric. Food Chem. 61, 10261-10272. https://doi.org/10.1021/jf402619d (2013).

12. Poms, R. E., Anklam, E. \& Kuhn, M. Polymerase chain reaction techniques for food allergen detection. J. AOAC Int. 87, 1391-1397. https://doi.org/10.1093/jaoac/87.6.1391 (2019).

13. Schubert-Ullrich, P. et al. Commercialized rapid immunoanalytical tests for determination of allergenic food proteins: An overview. Anal. Bioanal. Chem. 395, 69-81. https://doi.org/10.1007/s00216-009-2715-y (2009). 
14. Słowianek, M. \& Majak, I. Methods of allergen detection based on DNA analysis. Biotechnol. Food Sci. 76, 39-44. https://doi.org/ 10.34658/bfs.2011.75.2.39-44 (2011).

15. Verhoeckx, K. C. M. et al. Food processing and allergenicity. Food Chem. Toxicol. 80, 223-240. https://doi.org/10.1016/j.fct.2015. 03.005 (2015).

16. Mei, L. et al. Development and application of an antigen capture ELISA assay for diagnosis of Japanese encephalitis virus in swine, human and mosquito. Virol. J. 9, 4. https://doi.org/10.1186/1743-422X-9-4 (2012).

17. Walker, M. J., Burns, D. T., Elliott, C. T., Gowland, M. H. \& Mills, E. N. C. Is food allergen analysis flawed? Health and supply chain risks and a proposed framework to address urgent analytical needs. Analyst 141, 24-35. https://doi.org/10.1039/C5AN01457C (2016).

18. Wise, J. Covid-19: Lateral flow tests miss over half of cases, Liverpool pilot data show. BMJ 371, m4848. https://doi.org/10.1136/ bmj.m4848 (2020).

19. Koczula, K. M. \& Gallotta, A. Lateral flow assays. Essays Biochem. 60, 111-120. https://doi.org/10.1042/EBC20150012 (2016).

20. Sundhoro, M. et al. An electrochemical molecularly imprinted polymer sensor for rapid and selective food allergen detection. Food Chem. 344, 128648. https://doi.org/10.1016/j.foodchem.2020.128648 (2021).

21. Popa, O. M. \& Diculescu, V. C. Electrochemical behaviour of isoflavones genistein and biochanin A at a glassy carbon electrode. Electroanalysis 25, 1201-1208. https://doi.org/10.1002/elan.201200657 (2013).

22. 3M. Soy Protein Rapid Kit: Product Instructions. (2017). https://multimedia.3m.com/mws/media/1620974O/3m-soy-proteinrapid-kit-product-instructions.pdf. (Accessed 12 September 2021)

23. Huang, H., Liang, H. \& Kwok, K.-C. Effect of thermal processing on genistein, daidzein and glycitein content in soymilk. J. Sci. Food Agric. 86, 1110-1114. https://doi.org/10.1002/jsfa.2465 (2006).

24. Piao, Y.-Z. \& Eun, J.-B. Physicochemical characteristics and isoflavones content during manufacture of short-time fermented soybean product (cheonggukjang). J. Food Sci. Technol. 57, 2190-2197. https://doi.org/10.1007/s13197-020-04255-2 (2020).

25. Hefle, S. L., Lambrecht, D. M. \& Nordlee, J. A. Soy sauce retains allergenicity through the fermentation/production process. J. Allergy Clin. Immunol. 115, S32. https://doi.org/10.1016/j.jaci.2004.12.143 (2005).

26. Aoshima, H. \& Ooshima, S. Anti-hydrogen peroxide activity of fish and soy sauce. Food Chem. 112, 339-343. https://doi.org/10. 1016/j.foodchem.2008.05.069 (2009).

27. Magishi, N., Yuikawa, N., Kobayashi, M. \& Taniuchi, S. Degradation and removal of soybean allergen in Japanese soy sauce. Mol. Med. Rep. 16, 2264-2268. https://doi.org/10.3892/mmr.2017.6815 (2017).

28. Bush, R. K., Taylor, S. L., Nordlee, J. A. \& Busse, W. W. Soybean oil is not allergenic to soybean-sensitive individuals. J. Allergy Clin. Immunol. 76, 242-245. https://doi.org/10.1016/0091-6749(85)90709-2 (1985).

29. Steve, L. \& Taylor, J. L. B. Allergenicity of Soybean Lecithin. Expert Opinion Statement Food Allergy Research and Resource Program University of Nebraska (2017). https://farrp.unl.edu/documents/OpinionsSummaries/2017_0928_Soy\%20Lecithin.pdf. (Accessed 12 September 2021)

30. Zagon, J. et al. Peanut traces in packaged food products consumed by allergic individuals: Results of the MIRABEL project. J. Food Compos. Anal. 44, 196-204. https://doi.org/10.1016/j.jfca.2015.08.006 (2015).

31. Rodrigues, S. M. et al. Isolation and purification of RNA from tissues rich in polyphenols, polysaccharides, and pigments of annatto (Bixa orellana L.). Mol. Biotechnol. 37, 220-224. https://doi.org/10.1007/s12033-007-0070-9 (2007).

32. Kilmartin, P. A. \& Hsu, C. F. Characterisation of polyphenols in green, oolong, and black teas, and in coffee, using cyclic voltammetry. Food Chem. 82, 501-512. https://doi.org/10.1016/S0308-8146(03)00066-9 (2003).

33. Vignoli, J. A., Bassoli, D. G. \& Benassi, M. T. Antioxidant activity, polyphenols, caffeine and melanoidins in soluble coffee: The influence of processing conditions and raw material. Food Chem. 124, 863-868. https://doi.org/10.1016/j.foodchem.2010.07.008 (2011).

34. Moazzami, A. A. \& Kamal-Eldin, A. Sesame seed is a rich source of dietary lignans. J. Am. Oil Chem. Soc. 83, 719. https://doi.org/ 10.1007/s11746-006-5029-7 (2006).

35. Zeb, A., Muhammad, B. \& Ullah, F. Characterization of sesame (Sesamum indicum L.) seed oil from Pakistan for phenolic composition, quality characteristics and potential beneficial properties. J. Food Meas. Charact. 11, 1362-1369. https://doi.org/10.1007/ s11694-017-9514-5 (2017).

36. Smeds, A. I. et al. Quantification of a broad spectrum of lignans in cereals, oilseeds, and nuts. J. Agric. Food Chem. 55, 1337-1346. https://doi.org/10.1021/jf0629134 (2007).

37. Kajla, P., Sharma, A. \& Sood, D. R. Flaxseed-a potential functional food source. J. Food Sci. Technol. 52, 1857-1871. https://doi. org/10.1007/s13197-014-1293-y (2015).

38. Rodríguez-García, C., Sánchez-Quesada, C., Toledo, E., Delgado-Rodríguez, M. \& Gaforio, J. J. Naturally lignan-rich foods: A dietary tool for health promotion. Molecules 24, 917. https://doi.org/10.3390/molecules24050917 (2019).

39. Quinn, L. A. \& Tang, H. H. Antioxidant properties of phenolic compounds in macadamia nuts. J. Am. Oil Chem. Soc. 73, 1585-1588. https://doi.org/10.1007/BF02523529 (1996).

\section{Acknowledgements}

We would like to thank Blue Dragon restaurant in Boston, MA for providing restaurant dishes used in this work. This research did not receive any specific grant from funding agencies in the public, commercial, or not-forprofit sectors.

\section{Author contributions}

M.S. wrote the main manuscript text and prepared figures. M.S., S.R.A., and N.D.K. performed experiments. M.S., A.B., J.B., and L.M. conceived the experimental design and commented on manuscript text. All authors reviewed the manuscript.

\section{Competing interests}

The authors declare no competing interests.

\section{Additional information}

Supplementary Information The online version contains supplementary material available at https://doi.org/ 10.1038/s41598-021-00241-6.

Correspondence and requests for materials should be addressed to L.M.

Reprints and permissions information is available at www.nature.com/reprints. 
Publisher's note Springer Nature remains neutral with regard to jurisdictional claims in published maps and institutional affiliations.

(c) (i) Open Access This article is licensed under a Creative Commons Attribution 4.0 International License, which permits use, sharing, adaptation, distribution and reproduction in any medium or format, as long as you give appropriate credit to the original author(s) and the source, provide a link to the Creative Commons licence, and indicate if changes were made. The images or other third party material in this article are included in the article's Creative Commons licence, unless indicated otherwise in a credit line to the material. If material is not included in the article's Creative Commons licence and your intended use is not permitted by statutory regulation or exceeds the permitted use, you will need to obtain permission directly from the copyright holder. To view a copy of this licence, visit http://creativecommons.org/licenses/by/4.0/.

(C) The Author(s) 2021 